\title{
A Comprehensive Evaluation of Sustainable Development Ability and Pathway for Major Cities in China
}

\author{
Shih-Heng Yu ${ }^{1}$, Yu Gao ${ }^{1, *}$ and Yih-Chearng Shiue ${ }^{2}$ \\ 1 Department of Business Administration, National Central University, Zhongli 320, Taiwan; \\ shihhengyu@gmail.com or 101481026@cc.ncu.edu.tw \\ 2 Department of Information Management, National Central University, Zhongli 320, Taiwan; \\ ycs@mgt.ncu.edu.tw \\ * Correspondence: jzrhine@gmail.com or 104481601@cc.ncu.edu.tw; Tel.: +886-976-246-741
}

Received: 10 July 2017; Accepted: 20 August 2017; Published: 21 August 2017

\begin{abstract}
Sustainability consists of economic, environmental, and societal aspects. Concomitant with China's rapid growth, the evaluation of China's ability for sustainable development (SD) has become a topic of interest. Unlike previous studies that are based on provincial regions and focus on economic and/or environmental evaluations, we have evaluated the comprehensive SD ability of 34 major cities in China using the context-dependent data envelopment analysis (CD-DEA) and proposed benchmark-learning pathways. The results indicate that the SD ability of China's major cities may be classified and ordered from low tiers to high tiers: high energy consumption and polluting industries—intensive industries—fixed asset investments and service industries—innovation, quality of life and societal services industries. As a whole, cities along the coast have a higher ability for SD than inland cities, and southern cities also rate higher than northern cities. Cities that are prioritized by government policies and funding also have higher SD abilities than other cities. We recommend that cities with lower abilities (i.e., cities in the second, third, and fourth tiers) should adopt the following points in their developmental pathways (in this order): the control of energy consumption and environmental pollution, industry upgrading and redevelopment of the city, and the development of an environment that encourages innovation and provides ample employment. This study finds that GDP is no longer an issue that restricts the SD ability of China's major cities, as compared to other factors. As China progresses towards the sustainable cities, focus should be placed on the development of a knowledge-intensive economy, balanced development, and pollution prevention.
\end{abstract}

Keywords: sustainable development; China's cities; data envelopment analysis; efficiency evaluation; benchmark-learning pathway

\section{Introduction}

The rapid development of the mainland China over the past 40 years has been a topic of keen interest worldwide for some time. As China continues to develop, an unprecedented wave of urban development has now swept over the country; the increase in China's urban population far exceeds the total population of any country other than India. Urban development is necessary for developing the economy, increasing the income of a nation's citizens, and motivating societal progress. However, the negative effects that accompany urban development have affected the quality of life of the people, and the sustainable development (SD) of the cities themselves. Over the course of China's urban development, it is the development of the central cities that attracts the most attention. The Thirteenth Five-Year Plan of the Chinese government, which represents China's overall economic program, has placed significant focus on urban agglomeration and central cities; a list of these areas was also 
provided in the plan. Economic activities and urban functions are highly active in central cities, but the undesirable effects of urban development are most concentrated in these cities. These are also the first regions in China to encounter the "big city disease". Over past decades, the SD has extremely attracted many attentions of countries worldwide, including developing countries. With the rapid and impressive level of urbanization, conducting sustainability in city plan has become the one of the most important issues in China.

However, existing studies often treated provincial regions as decision-making units (DMUs), and the SD ability of cities has not been reported in a precise manner. Furthermore, the basic characteristics of each province (e.g., area, population, and natural environment) can differ dramatically, and even the environment and level of development within a province can vary significantly; these differences will have an effect on the conclusions of the aforementioned studies. In addition, Shen et al. [1] noted that the SD ability of a region is a comprehensive and holistic result that must encompass economic, environmental, and societal development. Most previous studies focus only on economic and environmental factors, and have yet to fully reflect on the true meaning of SD. To address the inadequacies of the aforementioned studies, we have evaluated the SD ability of China's cities based on a holistic view of SD. On this basis, we then developed schemes to improve SD ability, and also generated benchmark-learning pathways, which represents the best mathematical approximation optimization to catch up some (one or more) samples at a higher level. This study focused on central cities with minimal inner heterogeneity and numerical variations that also have the highest concentrations of population and economic value.

The remainder of this paper is organized as follows. Section 2 introduces the relevant research. In Section 3, the research method used in this study is introduced in detail. Section 4 appears data and analytical results relevant to sustainable efficiency and Section 5 provides the discussion on stepwise SD ability and pathway for 34 major cities in China. Summaries and conclusions will be drawn in Section 6.

\section{Literature and Theoretical Background}

Sustainable development (SD) means, "Development that meets the needs of current generations without compromising the ability of future generations to meet their needs and aspirations", and can be implemented in many different ways [2]. Sustainability recognizes the interdependence of ecological, social, and economic systems, which are the three pillars of sustainability [3]. Earlier SD theories focused on ecology and economics [4], and SD practices in the management field originated from the engineering realm; social behavior and development are treated as external boundary and non-essential conditions in the paradigm [5]. However, researchers have attached importance to social and cultural effects in recent years.

SD does not merely involve global and national level policies, as it is equally important at regional levels [6]. Many studies have already been performed on the SD ability of China's provinces. However, adapted to the engineering tradition mentioned above, most of them focused on energy and economic benefits. Lu and Lo [7] used economic development and waste discharge as evaluative indicators to horizontally compare the SD ability of 31 mainland provinces in China. Sueyoshi and Yuan [8] evaluated the relationships between economic development, energy consumption, and air pollution, and concluded that energy consumption needs to be reduced in four directly controlled municipalities, and the economic growth of the northwest region needs to be accelerated. Zhou and Ang [9] and Wang et al. [10] classified the sustainability of each province based on economic output, energy consumption, and pollution, while Tao et al. [11] adjusted the conclusions of these studies after accounting for the effects of power transmission modes. Chen et al. [12] introduced the Likert scale in the processing of data to study the production and energy efficiency of each province. In addition, based on energy efficiencies, Yang et al. [13] used the Super-efficiency DEA model to provide green development pathway plans for 31 provinces in China. 
The variation of population density between provinces in China is so wide that pressures on SD from contradictions between human and nature are very different. Chinese provinces have wide-ranging geographical conditions, from continuous mountains to coastal plains. Furthermore, their economic structures are also very different, with some based on agriculture and others being highly industrialized. At the city level, functions and environments are more consistent, with similar input and output variables, and cities play a huge role with small area in SD. At the same time, sustainable city is a very important topic in regional SD research. Ideally, a sustainable city is designed with the coverage of considerations of economic, environmental, and societal aspects. The data envelopment analysis (DEA) is one of the mainstream methods for evaluating efficiency; during the infancy of this method, the DEA method was considered suitable for studying economically complex cities, and it was also used to evaluate 28 major cities in China by the pioneer of the method [14]. $\mathrm{Zhu}$ [15] built on this research and compared the results of the DEA method with those obtained using other contemporary methods, and provided evidence for the effectiveness of this method. These studies were focused on evaluating the economic output of cities, and it was only later when the DEA method was used to evaluate the environment and sustainability of Chinese cities. Yuan et al. [16] used the DEA method to study the ability of 65 cities to respond to natural disasters, while Yang et al. [17] used this method to evaluate the sustainability of cities in Taiwan. However, no comprehensive assessment of the SD ability of Chinese cities has been performed. The reason for the low frequency of usage of the DEA method, as noted by Li et al. [18], is the limited availability of statistical data at the city level in China. In reality, the DEA method is perfectly suitable for comprehensive evaluation of a city's efficiency, and several case studies that have already been performed abroad using this method $[19,20]$. Studies that are related to the topic of this work are somewhat more common at the provincial level, due to the availability of data, but they still favor the engineering discipline. In addition to a comprehensive assessment, as noted by Mega [21], an increasing number of researchers has regarded sustainable city as a process rather than as an endpoint. Therefore, it is worthwhile to construct the benchmark-learning pathway as a stepwise progressive process towards sustainability.

\section{Methodology}

DEA, as developed by Charnes et al. [22], is a widely used non-parametric approach to measure the relative efficiency of DMUs with multiple inputs and outputs. So far, there are two types of measure in DEA, the radial measure introduced by Charnes et al. [22] and the slacks-based measure (SBM) presented by Tone [23]. Differ from radial measure, SBM has the following salient advantages: (1) it offers non-oriented evaluation that can simultaneously calculate slacks of inputs and output, and no need to artificially chose either input-oriented or output-oriented evaluations; (2) the efficient DMUs/benchmarks under SBM are guaranteed to be Pareto-efficient, and (3) it allows inefficient DMUs to improve their efficiencies by reducing inputs and/or increasing outputs in various proportions $[24,25]$. The context-dependent DEA (CD-DEA), originally introduced by Seiford and Zhu [26], is a well-known extension on standard DEA. The CD-DEA, consisting of stratification procedure, attractiveness measure, and progress measure, has proven a helpful method to construct the benchmark-learning pathway for inefficient DMUs $[27,28]$. Through the benchmark-learning pathway, inefficient DMUs can stepwise improve their efficiencies and reach the terminal frontier $[29,30]$. Generally, the CD-DEA is developed under radial measure, where the slack variables are not considered. In order to obtain a more complete benchmark-learning pathway, the SBM can be integrated into CD-DEA [31].

\subsection{SBM with Undesirable Outputs}

Suppose that there is a set of $n$ DMUs under evaluation, and each of which consumes $m$ inputs to produce $s$ outputs. The $i$ th input and $r$ th output of $\operatorname{DMU}_{j}(j=1, \ldots, n)$ are denoted 
by $x_{i j}(i=1, \ldots, m)$ and $y_{r j}(r=1, \ldots, s)$, respectively. The SBM evaluates efficiency of $\mathrm{DMU}_{o}$ by solving the following program.

$$
\begin{gathered}
\text { Minimize } \theta_{o}=\frac{1-\frac{1}{m} \sum_{i=1}^{m} s_{i}^{-} / x_{i o}}{1+\frac{1}{s} \sum_{r=1}^{+} s_{r}^{+} / y_{r o}} \\
\text { Subject to } x_{i o}=\sum_{j=1}^{n} \lambda_{j} x_{i j}+s_{i}^{-} \quad i=1, \ldots, m \\
y_{r o}=\sum_{j=1}^{n} \lambda_{j} y_{r j}-s_{r}^{+} \quad r=1, \ldots, s \\
\sum_{j=1}^{n} \lambda_{j}=1 \text { for VRS } \\
\lambda_{j} \geq 0, s_{i}^{-} \geq 0, s_{r}^{+} \geq 0 j=1, \ldots, n
\end{gathered}
$$

where $s_{i}^{-}$and $s_{r}^{+}$are the non-radial slack variable in $i$ th input and in the $r$ th output, respectively. The $\lambda_{j}$ is an intensity vector, referred to as a reference set, whose optimal values expose the proportions contributed by $\mathrm{DMU}_{j}$ in constructing the frontier. If the constraint $\sum_{j=1}^{n} \lambda_{j}=1$ is added, we can obtain the efficiency of $\mathrm{DMU}_{o}$ under variable returns to scale (VRS) assumption; otherwise, model (1) yields the efficiency with constant returns to scale (CRS).

Note that above model (1) neglects the effect arises from the undesirable outputs. It is clear that desirable outputs may come along with undesirable outputs as inputs consumes. Such concerns were commonly emphasized in SD literature. Thus, it is necessary to extend SBM by incorporating undesirable outputs into account [32]. The SBM with both desirable and undesirable outputs can be formulated as follows [33]:

$$
\begin{gathered}
\text { Minimize } \rho_{o}=\frac{1-\frac{1}{m} \sum_{i=1}^{m} s_{i}^{-} / x_{i o}}{1+\frac{1}{g+b}\left(\sum_{r=1}^{g} s_{r g}^{+g} / y_{r g o}^{g}+\sum_{r=1}^{b} s_{r b}^{-b} / y_{r b o}^{b}\right)} \\
\text { Subject to } x_{i o}=\sum_{j=1}^{n} \lambda_{j} x_{i j}+s_{i}^{-} i=1, \ldots, m \\
y_{r b o}^{b}=\sum_{j=1}^{n} \lambda_{j} y_{r b j}^{b}+s_{r b}^{-b} r b=1, \ldots, b \\
y_{r g o}^{g}=\sum_{j=1}^{n} \lambda_{j} y_{r g j}^{g}-s_{r g}^{+g} r g=1, \ldots, g \\
\sum_{j=1}^{n} \lambda_{j}=1 \text { for VRS } \\
\lambda_{j} \geq 0, s_{i}^{-} \geq 0, s_{r b}^{-b} \geq 0, s_{r g}^{+g} \geq 0 j=1, \ldots, n
\end{gathered}
$$

where $s_{r g}^{+g}$ and $s_{r b}^{-b}$ are the slack variables denoting shortages in desirable outputs and excesses in undesirable outputs, respectively. Through model (2), the $\mathrm{DMU}_{o}$ 's efficiency is ranged between zero and one, i.e., $0 \leq \rho_{0}^{*} \leq 1$, where " $" *$ " denotes the optimality. $\mathrm{ADMU}_{o}$ is said to be efficient if and only if $\rho_{o}^{*}=1$, or equivalently $\left(s_{i}^{-*}, s_{r g}^{+g *}, s_{r b}^{-b *}\right)=0$; otherwise, $\mathrm{DMU}_{o}$ is inefficient.

For an inefficient $\mathrm{DMU}_{o}$, it can improve the efficiency by retrenching the inputs $s_{i}^{-*}$, undesirable outputs $s_{r b}^{-b *}$, and/or expanding the desirable outputs $s_{r g}^{+g *}$, i.e., its improved target $\left(\hat{x}_{i o}, \hat{y}_{r b o}^{b}, \hat{y}_{r g o}^{g}\right)$ is defined by either $\left(\hat{x}_{i o}=x_{i o}-s_{i}^{-*}, \hat{y}_{r b o}^{b}=y_{r o}^{b}-s_{r b}^{-b *}, \hat{y}_{r g o}^{g}=y_{r o}^{g}+s_{r g}^{+g *}\right)$ or $\left(\hat{x}_{i o}=\sum_{j=1}^{n} \lambda_{j}^{*} x_{i j}\right.$, $\left.\hat{y}_{r b o}^{b}=\sum_{j=1}^{n} \lambda_{j}^{*} y_{r b j}^{b}, \hat{y}_{r g o}^{g}=\sum_{j=1}^{n} \lambda_{j}^{*} y_{r g j}^{g}\right)$. Note that the benchmarks for $\mathrm{DMU}_{o}$ are obtained by $L_{o}=\left\{\mathrm{DMU}_{j} \mid \lambda_{j}^{*}>0, j=1, \ldots, n\right\}$, indicating which $\mathrm{DMU}_{j}$ can be chosen as the learning entities for $\mathrm{DMU}_{0}$.

\subsection{Stratification Procedure in CD-DEA: Determining Performance Levels}

The idea behind stratification procedure is to sequentially partition $n$ DMUs into $p$ performance levels $(l=1, \ldots, p)$ by removing the upper frontier (lth-level) and then forming new 
frontier $((l+1)$ th-level $)$ consists of remaining DMUs over and over again until no DMU is left. Let $J^{1}=\left\{\mathrm{DMU}_{j}, j=1, . ., n\right\}$ be the set of all DMUs, and $E^{l}=\left\{\mathrm{DMU}_{o} \in J^{l} \mid \rho_{o}^{l *}=1\right\}$ denotes the set of efficient DMUs/benchmarks at $l$ th performance level, where $\rho_{o}^{l *}$ is the optimal value of the following program. The sequences of $J^{l}$ and $E^{l}$ are interactively defined as $J^{l+1}=J^{l}-E^{l}$.

$$
\begin{gathered}
\text { Minimize } \rho_{o}^{l}=\frac{1-\frac{1}{m} \sum_{i=1}^{m} s_{i}^{-} / x_{i o}}{1+\frac{1}{g+b}\left(\sum_{r=1}^{g} s_{r g}^{+g} / y_{r j}^{g}+\sum_{r=1}^{b} s_{r g}^{-b} / y_{r b j}^{b}\right)} \\
\text { Subject to } x_{i o}=\sum_{j \in J^{l}} \lambda_{j} x_{i j}+s_{i}^{-} i=1, \ldots, m \\
y_{r o}^{b}=\sum_{j \in J^{l}} \lambda_{j} y_{r b j}^{b}+s_{r}^{-b} r=1, \ldots, b \\
y_{r o}^{g}=\sum_{j \in J^{l}} \lambda_{j} y_{r g j}^{g}-s_{r}^{+g} r=1, \ldots, g \sum_{j \in J^{l}} \lambda_{j}=1 \text { for VRS } \\
\lambda_{j} \geq 0, s_{i}^{-} \geq 0, s_{r b}^{-b} \geq 0, s_{r g}^{+g} \geq 0, j \in J^{l}
\end{gathered}
$$

When $l=1$, model (3) is equivalent to model (2) and offers $E^{1}$ that represents benchmarks at 1 st performance level (i.e., the DMUs on the 1 st frontier). Subsequently, when $l=2$, model (3) offers benchmarks at 2nd performance level $E^{2}$ after the exclusion of $E^{1}$, and so on. Base on this manner, $p$ performance levels can be defined. The following algorithm accomplishes the process in identifying the set of DMUs of each performance level.

Step1: Set $l=1$ to evaluate all DMUs $J^{1}$ by model (3) to obtain the best-practice frontier that formed by $E^{1}$ (benchmarks at 1 st performance level).

Step2: Use $J^{l+1}=J^{l}-E^{l}$ to remove the DMUs on the upper frontier, if $J^{l+1}=\varnothing$, then algorithm stop. Step3: Evaluate new subset $J^{l+1}$ by model (3) to obtain the sub-frontier that formed by $E^{l+1}$ (benchmarks at lower $(l+1$ th) performance level).

Step4: Let $l=l+1$. Go to step2.

\subsection{Progress Measure in CD-DEA: Constructing the Benchmark-Learning Pathway}

As $p$ performance levels have been confirmed in above stratification procedure, $E^{l-1}$ should then be determined to complete the benchmark-learning pathway for $E^{l}(l=2, \ldots, p)$. Such a process, deemed as the progress measure, contributes DMUs at $l$ th performance level to find out the possible benchmarks at upper $((l-1)$ th) performance level stepwise guide them improve their efficiencies. The relative progress efficiency, improved target and possible benchmarks for a $\mathrm{DMU}_{o} \in E^{l o}\left(l_{o}=2, \ldots, p\right)$ with respect to upper level $E^{l o-1}$ can be obtained by following program.

$$
\begin{gathered}
\text { Minimize } \rho_{o}^{l o}=\frac{1-\frac{1}{m} \sum_{i=1}^{m} s_{i}^{-} / x_{i o}}{1+\frac{1}{g+b}\left(\sum_{r=1}^{g} s_{r g}^{+g} y_{r g j}^{g}+\sum_{r=1}^{b} s_{r g}^{-b} / y_{r b j}^{b}\right)} \\
\text { Subject to } x_{i o}=\sum_{j \in E^{l o-1}} \lambda_{j} x_{i j}+s_{i}^{-} i=1, \ldots, m \\
y_{r b o}^{b}=\sum_{j \in E^{l o-1}} \lambda_{j} y_{r b j}^{b}+s_{r}^{-b} r b=1, \ldots, b \\
y_{r g o}^{g}=\sum_{j \in E^{l o-1}} \lambda_{j} y_{r g j}^{g}-s_{r}^{+g} r g=1, \ldots, g \\
\sum_{j \in E^{l o-1}} \lambda_{j}=1 \text { for VRS } \\
\lambda_{j} \geq 0, s_{i}^{-} \geq 0, s_{r b}^{-b} \geq 0, s_{r g}^{+g} \geq 0, j \in E^{l o-1}
\end{gathered}
$$

where $j \in E^{l o-1}$ indicates that progress for $\mathrm{DMU}_{o} \in E^{l o}$ is a level-by-level improvement; $s_{i}^{-}, s_{r g}^{+g}$ and $s_{r b}^{-b}$ are the slack variables, denoting excesses in inputs, shortages in desirable outputs and excesses in undesirable outputs, respectively. Theses slacks represent the performance gap between DMUs at upper $((l-1)$ th) performance level and those at the lower $(l$ th) performance level. The progress efficiency $\rho_{o}^{l o *}$ between zero and one is monotonic decreasing in $s_{i}^{-*}, s_{r g}^{+g *}$ and $s_{r b}^{-b *}$. The improved 
$\operatorname{target}\left(\hat{x}_{i o}, \hat{y}_{r b o}^{b}, \hat{y}_{r g o}^{g}\right) \in E^{l o-1}$ for $\operatorname{DMU}_{o} \in E^{l o}$ can be defined by $\left(\hat{x}_{i o}=x_{i o}-s_{i}^{-*}, \hat{y}_{r b o}^{b}=y_{r o}^{b}-s_{r b}^{-b *}\right.$, $\left.\hat{y}_{r g o}^{g}=y_{r o}^{g}+s_{r g}^{+g *}\right)$. In addition, based on the intensity vector $\lambda_{j}^{*}$, the possible benchmarks for a $\mathrm{DMU}_{o} \in E^{l o}\left(l_{o}=2, \ldots, p\right)$ is given by $B_{o}^{l o}=\left\{\mathrm{DMU}_{j} \in E^{l o-1} \mid \lambda_{j}^{*}>0\right\}$.

\section{Empirical Application on Constructing SD Pathway for Major Cities}

\subsection{Sample}

All of the cities included within the urban agglomeration plan in the 2015 "Outline of the 13th Five-Year Plan for the National Economic and Social Development of the People's Republic of China" were included in the sample library of this study, for a total of 34 samples. The inputs include electricity consumption, fixed investments, and labors [34,35]. The outputs include the three components of SD-economic, environmental, and societal development, with each component having its own set of indicators. The gross domestic product (GDP) is the economic indicator [36,37], while the environmental indicators include $\mathrm{PM}_{2.5}$ and the air pollution index [38,39]. In view of the completeness of the available data, the government social security and employment expenditure (SEEE) and the town's unemployment rate were used as societal indicators $[40,41]$. The data was obtained from the official annual statistics of each city in 2015. Table 1 presents the descriptive statistics of all inputs and outputs.

Table 1. Descriptive statistics for the 34 major cities.

\begin{tabular}{cccccc}
\hline & Maximum & Minimum & Mean & Std. Dev. & N \\
\hline Inputs & & & & & \\
Electricity consumption (billion kwh) & 1369.02 & 60.32 & 404.55 & 280.36 & 34 \\
Labors (10 thousand) & 1696.94 & 103.87 & 527.15 & 350.25 & 34 \\
Fixed investments (RMB\$100 million) & $13,223.75$ & 824.57 & 4589.67 & 2750.10 & 34 \\
\hline Outputs & & & & & \\
GDP (RMB\$100 million) & $23,567.70$ & 1065.78 & 7379.71 & 5649.60 & 34 \\
SEEE (10 thousand) & $5,090,079.00$ & $208,848.00$ & $1,162,733.71$ & $1,332,142.40$ & 34 \\
Unemployment rate & 4.20 & 1.31 & 2.86 & 0.74 & 34 \\
Air Pollution Index & 8.80 & 2.49 & 5.83 & 1.55 & 34 \\
PM $_{2.5}$ (ug/m m $^{3}$ & 96.00 & 22.00 & 55.94 & 18.01 & 34 \\
\hline
\end{tabular}

\subsection{Results}

The relative efficiencies of 34 major cities obtained by model (2) are listed in Table 2, eight cities (Beijing, Changsha, Dalian, Guangzhou, Guiyang, Shanghai, Shenzhen, Chongqing) are deemed as efficient and place on frontier $\left(\rho_{o}^{*}=1\right)$, while the remaining 26 cities are determined to be inefficient $\left(\rho_{o}^{*}<1\right)$. By using model $(2)$, the benchmark set $L_{o}$ for 26 inefficient cities are shown in last column, which indicate the learning entities of inefficient cities. Take Changchun city ranked second $\left(\rho_{o}^{*}=0.640\right)$ as an example, for reaching the frontier or becoming an efficient one, it has to refer to Beijing and Changsha cities. Note that model (2) can only provide the benchmarks as terminal goal of sustainability to inefficient cities. Such benchmarking information perhaps is impractical since not all inefficient cities can outright improve their efficiencies in a single step. Moreover, it is not reasonable that most of inefficient cities should select Beijing as the benchmark because there may exist a huge gap between them. 
Table 2. Efficiency results of 34 major cities via model (2).

\begin{tabular}{cccccccc}
\hline Major Cities & Score & Rank & Benchmarks $L_{\boldsymbol{o}}$ & Major Cities & Score & Rank & Benchmarks $L_{\boldsymbol{o}}$ \\
\hline Beijing & 1.000 & 1 & Beijing & Wuhan & 0.593 & 11 & Beijing \\
Changsha & 1.000 & 1 & Changsha & Xiamen & 0.416 & 12 & Changsha \\
Dalian & 1.000 & 1 & Dalian & Chengdu & 0.416 & 13 & Dalian \\
Guangzhou & 1.000 & 1 & Guangzhou & Fuzhou & 0.333 & 14 & Guangzhou \\
Guiyang & 1.000 & 1 & Guiyang & Haikou & 0.345 & 15 & Guiyang \\
Shanghai & 1.000 & 1 & Shanghai & Hefei & 0.374 & 16 & Shanghai \\
Shenzhen & 1.000 & 1 & Shenzhen & Hohhot & 0.417 & 17 & Shenzhen \\
Chongqing & 1.000 & 1 & Chongqing & Kunming & 0.331 & 18 & Chongqing \\
Changchun & 0.640 & 2 & Beijing, Changsha & Nanchang & 0.428 & 19 & Beijing, Changsha \\
Harbin & 0.633 & 3 & Beijing, Changsha, Dalian & Taiyuan & 0.324 & 20 & Beijing, Changsha, Dalian \\
Hangzhou & 0.474 & 4 & Beijing & Xian & 0.379 & 21 & Beijing \\
Jinan & 0.340 & 5 & Beijing & Xining & 0.195 & 22 & Beijing \\
Nanjing & 0.500 & 6 & Beijing & Yinchuan & 0.322 & 23 & Beijing \\
Qingdao & 0.619 & 7 & Beijing, Changsha & Zhengzhou & 0.328 & 24 & Beijing, Changsha \\
Shenyang & 0.571 & 8 & Beijing, Changsha, Dalian & Lanzhou & 0.238 & 25 & Beijing, Changsha, Dalian \\
Tianjin & 0.590 & 9 & Beijing & Nanning & 0.328 & 26 & Beijing \\
Urumqi & 0.478 & 10 & Beijing & Shijiazhuang & 0.260 & 27 & Beijing \\
\hline
\end{tabular}

By using the stratification procedure in CD-DEA, model (3), 34 major cities can be partitioned into 4 levels $\left(E^{l}, l=1, \ldots, 4\right)$ reported in Table 3. The first level $E^{l=1}$ involves \{Shanghai, Dalian, Guangzhou, Beijing, Changsha, Chongqing, Shenzhen, Guiyang\}; the second level $E^{l=2}$ covers \{Tianjin, Changchun, Shenyang, Hangzhou, Wuhan, Qingdao, Nanjing, Harbin, Jinan, Xiamen, Urumqi\}; the third level $E^{l=3}$ includes \{Taiyuan, Hefei, Chengdu, Xining, Xian, Hohhot, Kunming, Nanchang, Haikou, Yinchuan, Fuzhou, Zhengzhou\}; finally, the fourth level $E^{l=4}$ comprises \{Shijiazhuang, Nanning, Lanzhou\}. Technically, the cities in first level $E^{l=1}$ obtained from model (3) are the most efficient among sampling cities, which are equivalent to those obtained from model (2) while the cities in second level $E^{l=2}$ is calculated via the exclusion of $E^{l=1}$, and so on. The stratification procedure stop at $l=4$ since no cities left after removing $E^{l=4}$, i.e., $J^{l=5}=\varnothing$.

Table 3. Stratified efficiencies and performance levels for 34 major cities.

\begin{tabular}{cccccc}
\hline Major Cities & $\boldsymbol{E}^{\mathbf{1}}$ & $\boldsymbol{E}^{\mathbf{2}}$ & $\boldsymbol{E}^{\mathbf{3}}$ & $\boldsymbol{E}^{\mathbf{4}}$ & Level \\
\hline Shanghai & 1.000 & - & - & - & Level 1 \\
Dalian & 1.000 & - & - & - & Level 1 \\
Guangzhou & 1.000 & - & - & - & Level 1 \\
Beijing & 1.000 & - & - & - & Level 1 \\
Changsha & 1.000 & - & - & - & Level 1 \\
Chongqing & 1.000 & - & - & - & Level 1 \\
Shenzhen & 1.000 & - & - & - & Level 1 \\
Guiyang & 1.000 & - & - & - & Level 1 \\
Tianjin & 0.590 & 1.000 & - & - & Level 2 \\
Changchun & 0.640 & 1.000 & - & - & Level 2 \\
Shenyang & 0.571 & 1.000 & - & - & Level 2 \\
Hangzhou & 0.474 & 1.000 & - & - & Level 2 \\
Wuhan & 0.593 & 1.000 & - & - & Level 2 \\
Qingdao & 0.619 & 1.000 & - & - & Level 2 \\
Nanjing & 0.500 & 1.000 & - & - & Level 2 \\
Harbin & 0.633 & 1.000 & - & - & Level 2 \\
Jinan & 0.340 & 1.000 & - & - & Level 2 \\
Xiamen & 0.416 & 1.000 & - & - & Level 2 \\
Urumqi & 0.478 & 1.000 & - & - & Level 2 \\
Taiyuan & 0.324 & 0.474 & 1.000 & - & Level 3 \\
Hefei & 0.374 & 0.547 & 1.000 & - & Level 3 \\
Chengdu & 0.416 & 0.792 & 1.000 & - & Level 3 \\
Xining & 0.195 & 0.373 & 1.000 & - & Level 3 \\
Xian & 0.379 & 0.545 & 1.000 & - & Level 3 \\
Hohhot & 0.417 & 0.666 & 1.000 & - & Level 3 \\
Kunming & 0.331 & 0.517 & 1.000 & - &
\end{tabular}


Table 3. Cont.

\begin{tabular}{cccccc}
\hline Major Cities & $\boldsymbol{E}^{\mathbf{1}}$ & $\boldsymbol{E}^{\mathbf{2}}$ & $\boldsymbol{E}^{\mathbf{3}}$ & $\boldsymbol{E}^{\mathbf{4}}$ & Level \\
\hline Nanchang & 0.428 & 0.598 & 1.000 & - & Level 3 \\
Haikou & 0.345 & 0.547 & 1.000 & - & Level 3 \\
Yinchuan & 0.322 & 0.424 & 1.000 & - & Level 3 \\
Fuzhou & 0.333 & 0.540 & 1.000 & - & Level 3 \\
Zhengzhou & 0.328 & 0.618 & 1.000 & - & Level 3 \\
Shijiazhuang & 0.260 & 0.386 & 0.527 & 1.000 & Level 4 \\
Nanning & 0.328 & 0.478 & 0.778 & 1.000 & Level 4 \\
Lanzhou & 0.238 & 0.359 & 0.565 & 1.000 & Level 4 \\
\hline
\end{tabular}

To find out the possible benchmarks and make level-by-level improvement for inefficient cities in $E^{l=2}, E^{l=3}$ and $E^{l=4}$, the progress measure, model (4), is then applied. The results of optimal solution to model (4) are shown in Table 4 , where column 4 reports the benchmarks $B_{o}^{l o}=\left\{\mathrm{DMU}_{j} \in E^{l o-1} \mid \lambda_{j}^{*}>0\right\}$ for inefficient cities in $E^{l o}$ on the SD pathway from $\mathrm{L}_{l o}$ to $\mathrm{L}_{l o-1}$ and column 5 to 12 show the potential improvement of energy consumption, labors, fixed investments, GDP, SEEE, unemployment rate, air pollution index and $\mathrm{PM}_{2.5}$ in percentage terms (\%), calculated by optimal slack variable divided by the raw data for each input, desirable output and undesirable output, i.e., $s_{i}^{-*} / x_{i o}, s_{r g}^{+g} / y_{r g o}^{g}$ and $s_{r b}^{-b} / y_{r b o}^{b}$. For example, in terms of SD pathway L3 to L2, Chengdu in $E^{l=3}$ can choose \{Tianjin, Hangzhou, Wuhan, Qingdao\}as the benchmarks and make potential improvement on retracting labors $(26.66 \%)$, unemployment rate $(0.5 \%)$ and air pollution index (4.03\%), and expanding SEEE $(70.95 \%)$. The outcomes of these analyses can be visualized in a geographical view, the following Figures 1-3 respectively demonstrate the SD pathways of L2 to L1, L3 to L2 and L4 to L3.

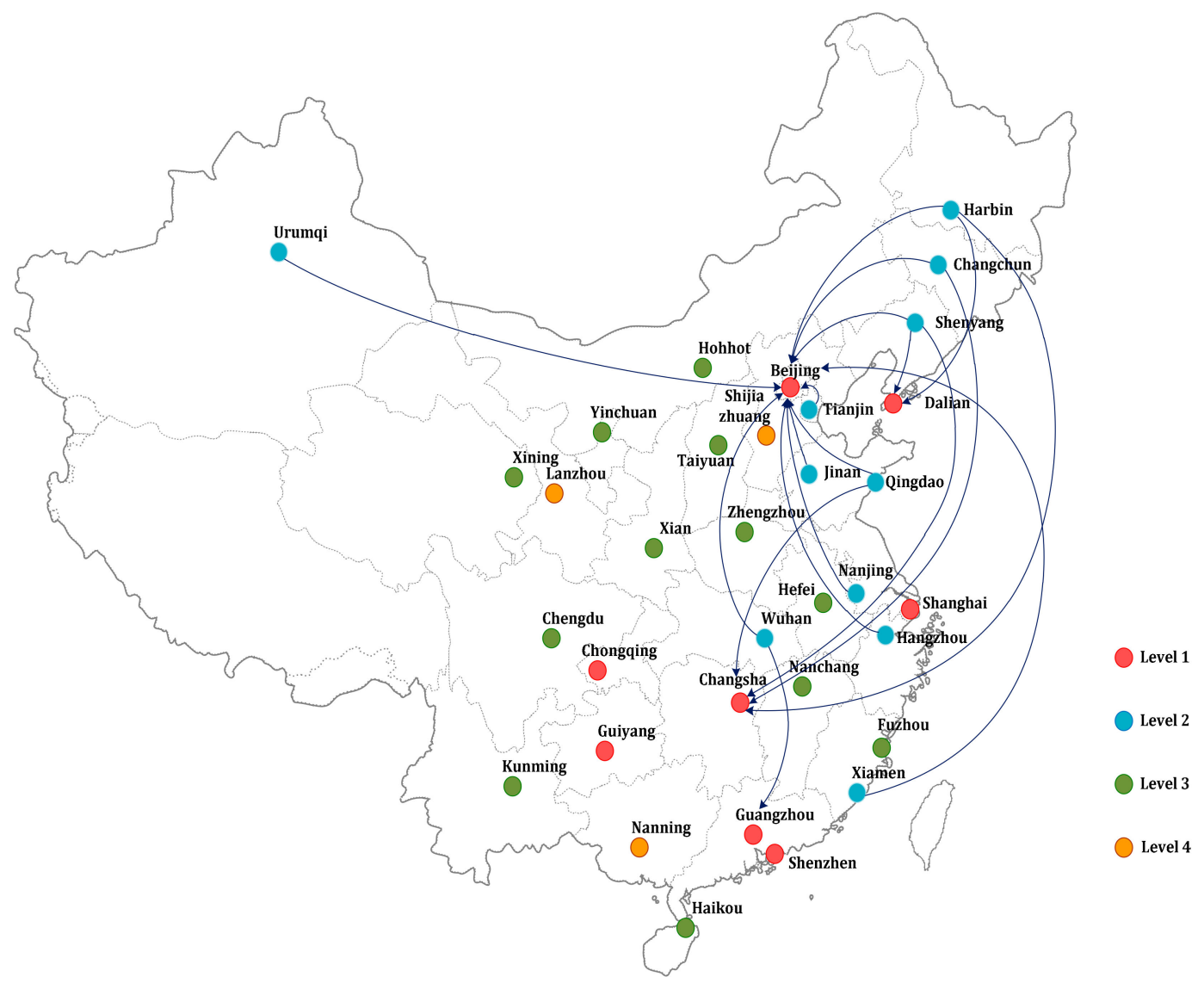

Figure 1. Benchmark-learning pathway from L2 to L1. 
Table 4. Benchmark-learning pathway and improvement on variable for 34 major cities

\begin{tabular}{|c|c|c|c|c|c|c|c|c|c|c|c|}
\hline $\begin{array}{l}\text { Major } \\
\text { Cities }\end{array}$ & No. & $\begin{array}{c}\text { SD } \\
\text { Pathway }\end{array}$ & $B_{o}^{l o}$ & $\begin{array}{c}\text { Electricity } \\
\text { Consumption }\end{array}$ & Labors & $\begin{array}{c}\text { Fixed } \\
\text { Investments }\end{array}$ & GDP & SEEE & $\begin{array}{c}\text { Unemployment } \\
\text { Rate }\end{array}$ & $\begin{array}{l}\text { Air Pollution } \\
\text { Index }\end{array}$ & $\mathbf{P M}_{2.5}$ \\
\hline Shanghai & (11) & L1 & - & $0.00 \%$ & $0.00 \%$ & $0.00 \%$ & $0.00 \%$ & $0.00 \%$ & $0.00 \%$ & $0.00 \%$ & $0.00 \%$ \\
\hline Dalian & (12) & L1 & - & $0.00 \%$ & $0.00 \%$ & $0.00 \%$ & $0.00 \%$ & $0.00 \%$ & $0.00 \%$ & $0.00 \%$ & $0.00 \%$ \\
\hline Guangzhou & (13) & L1 & - & $0.00 \%$ & $0.00 \%$ & $0.00 \%$ & $0.00 \%$ & $0.00 \%$ & $0.00 \%$ & $0.00 \%$ & $0.00 \%$ \\
\hline Changsha & (15) & L1 & - & $0.00 \%$ & $0.00 \%$ & $0.00 \%$ & $0.00 \%$ & $0.00 \%$ & $0.00 \%$ & $0.00 \%$ & $0.00 \%$ \\
\hline Chongqing & (16) & L1 & - & $0.00 \%$ & $0.00 \%$ & $0.00 \%$ & $0.00 \%$ & $0.00 \%$ & $0.00 \%$ & $0.00 \%$ & $0.00 \%$ \\
\hline Shenzhen & (17) & L1 & - & $0.00 \%$ & $0.00 \%$ & $0.00 \%$ & $0.00 \%$ & $0.00 \%$ & $0.00 \%$ & $0.00 \%$ & $0.00 \%$ \\
\hline Guiyang & (18) & L1 & - & $0.00 \%$ & $0.00 \%$ & $0.00 \%$ & $0.00 \%$ & $0.00 \%$ & $0.00 \%$ & $0.00 \%$ & $0.00 \%$ \\
\hline Tianjin & (21) & $\mathrm{L} 2 \rightarrow \mathrm{L} 1$ & $\{(14)\}$ & $-14.04 \%$ & $-2.78 \%$ & $-52.16 \%$ & $0.00 \%$ & $44.59 \%$ & $-73.17 \%$ & $-20.37 \%$ & $-14.69 \%$ \\
\hline Shenyang & (23) & $\mathrm{L} 2 \rightarrow \mathrm{L} 1$ & $\{(12),(14),(15)\}$ & $0.00 \%$ & $-9.04 \%$ & $-54.25 \%$ & $0.00 \%$ & $0.00 \%$ & $-73.43 \%$ & $-61.59 \%$ & $-56.40 \%$ \\
\hline Hangzhou & (24) & $\mathrm{L} 2 \rightarrow \mathrm{L} 1$ & $\{(14)\}$ & $-27.11 \%$ & $-23.77 \%$ & $-34.10 \%$ & $0.00 \%$ & $102.93 \%$ & $-69.27 \%$ & $-44.50 \%$ & $-38.67 \%$ \\
\hline Wuhan & (25) & $\mathrm{L} 2 \rightarrow \mathrm{L} 1$ & $\{(13),(14)\}$ & $-0.03 \%$ & $0.00 \%$ & $-50.92 \%$ & $0.00 \%$ & $25.07 \%$ & $-75.32 \%$ & $-49.27 \%$ & $-49.87 \%$ \\
\hline Qingdao & $(26)$ & $\mathrm{L} 2 \rightarrow \mathrm{L} 1$ & $\{(14),(15)\}$ & $0.00 \%$ & $-17.69 \%$ & $-29.49 \%$ & $0.00 \%$ & $84.88 \%$ & $-52.52 \%$ & $-28.71 \%$ & $-14.27 \%$ \\
\hline Naniing & (27) & $\mathrm{L} 2 \rightarrow \mathrm{L} 1$ & $\{(14)\}$ & $-17.96 \%$ & $-2.16 \%$ & $-42.73 \%$ & $0.00 \%$ & $122.08 \%$ & $-78.33 \%$ & $-49.53 \%$ & $-41.24 \%$ \\
\hline Harbin & $(28)$ & $\mathrm{L} 2 \rightarrow \mathrm{L} 1$ & $\{(12),(14),(15)\}$ & $0.00 \%$ & $-38.82 \%$ & $-9.94 \%$ & $0.00 \%$ & $0.00 \%$ & $-58.38 \%$ & $-50.24 \%$ & $-52.59 \%$ \\
\hline Jinan & (29) & $\mathrm{L} 2 \rightarrow \mathrm{L} 1$ & $\{(14)\}$ & $-36.02 \%$ & $-18.87 \%$ & $-33.22 \%$ & $0.00 \%$ & $391.58 \%$ & $-84.18 \%$ & $-77.14 \%$ & $-75.65 \%$ \\
\hline Xiamen & (20) & $\mathrm{L} 2 \rightarrow \mathrm{L} 1$ & $\{(14)\}$ & $-31.57 \%$ & $-37.85 \%$ & $-26.22 \%$ & $0.00 \%$ & $103.73 \%$ & $-93.36 \%$ & $-65.28 \%$ & $-57.14 \%$ \\
\hline Urumgi & (2a) & $\mathrm{L} 2 \rightarrow \mathrm{L} 1$ & $\{(14)\}$ & $-28.13 \%$ & $-19.23 \%$ & $-14.05 \%$ & $0.00 \%$ & $62.28 \%$ & $-95.82 \%$ & $-87.77 \%$ & $-85.84 \%$ \\
\hline Taiyuan & (31) & $\mathrm{L} 3 \rightarrow \mathrm{L} 2$ & $\{(24),(25)\}$ & $-55.25 \%$ & $-37.93 \%$ & $0.00 \%$ & $0.00 \%$ & $0.97 \%$ & $-77.01 \%$ & $-76.77 \%$ & $-71.73 \%$ \\
\hline Hefei & (32) & $\mathrm{L} 3 \rightarrow \mathrm{L} 2$ & $\{(25),(26)\}$ & $0.00 \%$ & $-45.30 \%$ & $-33.42 \%$ & $0.00 \%$ & $45.36 \%$ & $-44.72 \%$ & $-37.44 \%$ & $-46.23 \%$ \\
\hline Xining & (34) & $\mathrm{L} 3 \rightarrow \mathrm{L} 2$ & $\{(23)\}$ & $-89.31 \%$ & $-43.20 \%$ & $-0.26 \%$ & $19.08 \%$ & $0.00 \%$ & $-78.24 \%$ & $-77.10 \%$ & $-73.73 \%$ \\
\hline Xian & (35) & $\mathrm{L} 3 \rightarrow \mathrm{L} 2$ & $\{(25)\}$ & $-11.79 \%$ & $-45.71 \%$ & $-35.30 \%$ & $0.00 \%$ & $3.20 \%$ & $-49.46 \%$ & $-46.43 \%$ & $-34.17 \%$ \\
\hline Hohhot & (36) & $\mathrm{L} 3 \rightarrow \mathrm{L} 2$ & $\{(24),(25),(27),(2 \mathrm{a})\}$ & $-20.71 \%$ & $0.00 \%$ & $0.00 \%$ & $0.00 \%$ & $0.00 \%$ & $-77.73 \%$ & $-66.66 \%$ & $-54.72 \%$ \\
\hline Kunming & (37) & $\mathrm{L} 3 \rightarrow \mathrm{L} 2$ & $\{(21)\}$ & $-31.89 \%$ & $-48.90 \%$ & $-12.32 \%$ & $0.00 \%$ & $2.07 \%$ & $-63.68 \%$ & $-56.52 \%$ & $-44.91 \%$ \\
\hline Nanchang & (38) & $\mathrm{L} 3 \rightarrow \mathrm{L} 2$ & $\{(25),(26)\}$ & $0.00 \%$ & $-34.07 \%$ & $-27.09 \%$ & $0.00 \%$ & $7.68 \%$ & $-65.88 \%$ & $-47.71 \%$ & $-44.35 \%$ \\
\hline Haikou & (39) & $\mathrm{L} 3 \rightarrow \mathrm{L} 2$ & $\{(23),(25),(28)\}$ & $-24.66 \%$ & $-52.92 \%$ & $0.00 \%$ & $0.00 \%$ & $0.00 \%$ & $-63.64 \%$ & $-60.51 \%$ & $-53.08 \%$ \\
\hline Yinchuan & (30) & $\mathrm{L} 3 \rightarrow \mathrm{L} 2$ & $\{(23),(25)\}$ & $-36.87 \%$ & $-40.54 \%$ & $-30.55 \%$ & $0.00 \%$ & $0.00 \%$ & $-87.81 \%$ & $-85.98 \%$ & $-81.03 \%$ \\
\hline Fuzhou & (3a) & $\mathrm{L} 3 \rightarrow \mathrm{L} 2$ & $\{(21)\}$ & $-27.17 \%$ & $-40.37 \%$ & $-13.49 \%$ & $0.00 \%$ & $67.42 \%$ & $-51.11 \%$ & $-36.21 \%$ & $-20.66 \%$ \\
\hline Zhengzhou & $(3 \mathrm{~b})$ & $\mathrm{L} 3 \rightarrow \mathrm{L} 2$ & $\{(21),(24)$ & $-19.10 \%$ & $-13.12 \%$ & $-29.90 \%$ & $0.00 \%$ & $31.35 \%$ & $0.00 \%$ & $-52.89 \%$ & $-57.26 \%$ \\
\hline Shijiazhuang & $(41)$ & $\mathrm{L} 4 \rightarrow \mathrm{L} 3$ & $\{(33),(35)\}$ & $-44.95 \%$ & $-15.79 \%$ & $-27.79 \%$ & $0.00 \%$ & $0.00 \%$ & $-52.78 \%$ & $-56.73 \%$ & $-59.79 \%$ \\
\hline Nanning & $(42)$ & $\mathrm{L} 4 \rightarrow \mathrm{L} 3$ & $\{(33),(35),(37),(39)\}$ & $0.00 \%$ & $-38.33 \%$ & $0.00 \%$ & $0.00 \%$ & $0.00 \%$ & $-33.34 \%$ & $-10.07 \%$ & $-17.05 \%$ \\
\hline Lanzhou & (43) & $\mathrm{L} 4 \rightarrow \mathrm{L} 3$ & $\{(33),(37)\}$ & $-58.53 \%$ & $-4.20 \%$ & $-4.83 \%$ & $0.00 \%$ & $0.00 \%$ & $-40.66 \%$ & $-72.87 \%$ & $-71.76 \%$ \\
\hline
\end{tabular}




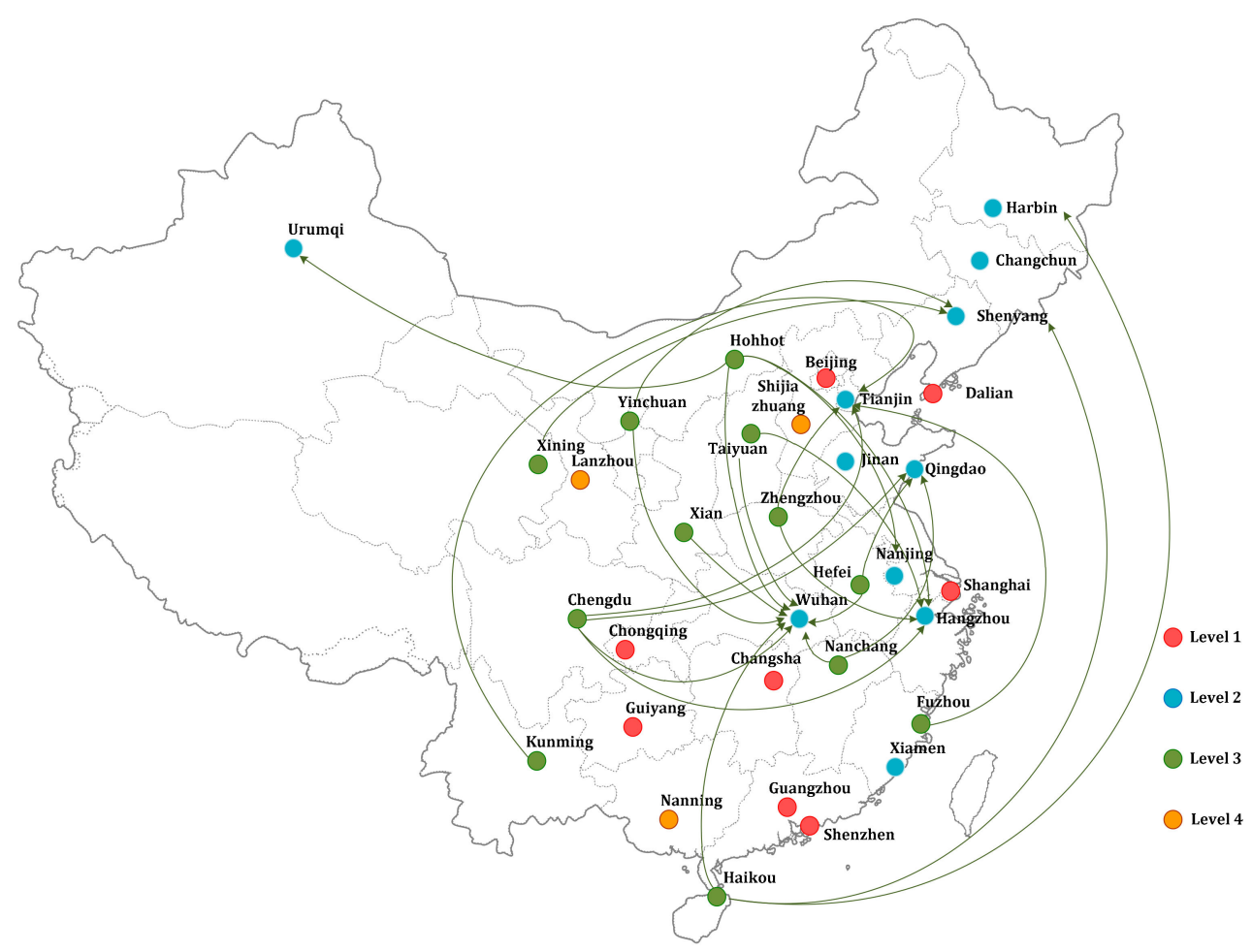

Figure 2. Benchmark-learning pathway from L3 to L2.

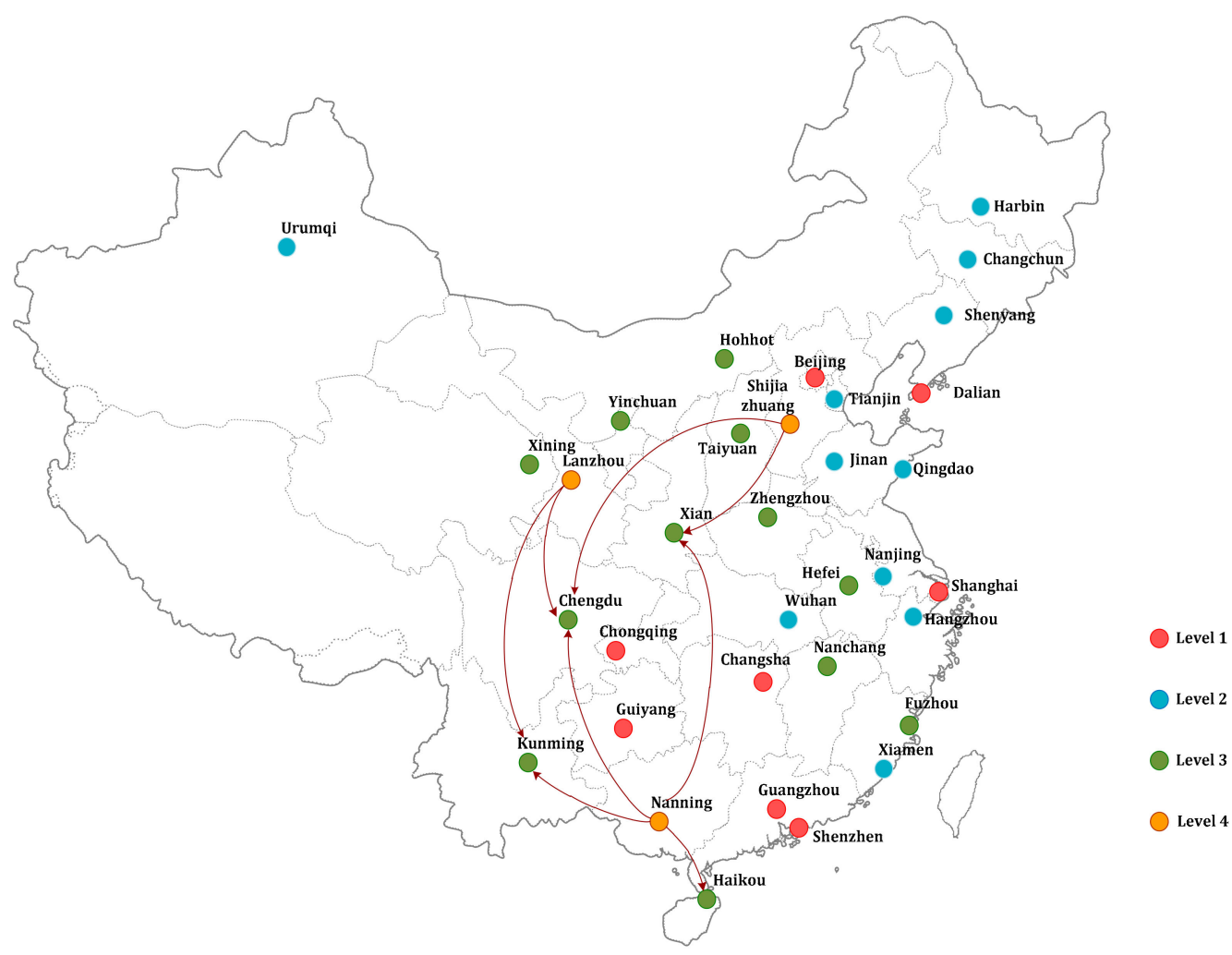

Figure 3. Benchmark-learning pathway from L4 to L3.

The intrinsic meaning of the benchmark-learning pathway is that the distance in the multi-dimensional mapping is the shortest and significant; therefore, there may be more than one learning path. This means that developing along learning pathways is easier and more efficient than 
learning other cities, and it provides resource optimization, reduction of redundant construction, and more reliability. The improvement on variable means the amount of improvement needed to achieve the overall level of a higher tier. To most variables, negative values mean improvement but positive to SEEE.

\section{Discussion}

The cities that occupy the frontrunner positions in terms of efficiency include: Beijing, Shanghai, Guangzhou, Shenzhen, Chongqing, Dalian and Guiyang. The SD abilities of the first four cities are especially outstanding. The reasons for this observation are as follows: firstly, these cities have outgrown their reliance on conventional industries and fixed investments, and consequently have very high levels of economic efficiency. Secondly, these cities have immense financial and political power, and are able to invest more heavily in sustainable environmental and societal development. A more subtle cause is that these cities have a special role and status in China, and are widely regarded as first-rate cities; therefore, these cities will also receive larger quantities of "soft" resources. Chongqing, which is a directly-controlled municipality, also enjoys a similar advantage and has experienced tremendous growth in recent years. The population of Chongqing changed from a net outflow into a net inflow, and its potential for further development has received widespread interest. Guiyang is China's first "National Forest City", and its SD ability is largely supported by its environmental advantages. In addition, Guiyang is now benefitting from substantial fixed asset investments that were made over the last few years and is developing rapidly despite its weak economic fundamentals; this is largely consistent with the estimates made in this study. Cities within the first tier have the highest efficiencies, and have the strongest combined "economic-societal-environmental" sustainability. These cities generally have very high production efficiency due to the development of technological industries and innovation-driven enterprises.

Cities within the second tier include Tianjin, Wuhan, Nanjing, Hangzhou, Xiamen, Shenyang, Changchun, Harbin, Jinan, Qingdao, and Urumqi. The differences between these cities and the frontrunners in terms of efficiency are mainly due to three aspects: reliance on fixed asset investments $(+45.4 \%$ on average), lower public service investments $(-46.1 \%$ on average), and inadequate employment opportunities (all samples need further improvement); some of these cities also have environmental pollution issues that need to be addressed. As a whole, these cities are undergoing major changes that are driven by large-scale investments, and have yet to put any special focus on $\mathrm{SD}$. In terms of learning roadmaps, Beijing is the benchmark-learning pathway for a number of cities; in other words, if these cities are to improve their ability for SD, they need to reduce their reliance on fixed asset investments, increase employment opportunities, and provide more public services. The benchmark-learning pathway of cities such as Shenyang point towards Guangzhou, Changsha, and Dalian instead, which reflects on the need of these cities to reduce pollution.

Cities in the third tier include Fuzhou, Hefei, Zhengzhou, Nanchang, Haikou, Hohhot, Taiyuan, Chengdu, $\mathrm{Xi}^{\prime}$ an, Kunming, Xining, and Yinchuan. As compared to cities in the previous tier, some the inadequacies of these cities include: higher energy consumption and manual labor investments, and lower employment levels; some of these cities also have significant environmental risks. Emerging industries and service industries have yet to be adequately developed in these cities, and conventional industries remain dominant in these locations. The SD ability of these cities is therefore, relatively weak. In some of these cities, large-scale conventional production industries are still being developed in the near-term; this is incompatible with SD. Hangzhou (which is a second-tier city) is an example for the transformation of conventional industries towards a center for technological development and entrepreneurship, and thus receives the largest number of recommendations in terms of benchmark-learning roadmaps from third-tier cities. This indicates that the development of information, cultural, and modern service industries will enhance the SD ability of third-tier cities. Tianjin, Wuhan, and Qingdao also received numerous recommendations. This is because these cities provide ample opportunities for employment, invest strongly in societal services, and are fertile 
grounds for the development of emerging industries. These are also aspects that need to be improved upon in third-tier cities. In reality, if Suzhou was also included in this evaluation, it would become the focal point for learning pathways from cities in this tier, as it also has ample employment opportunities and substantial public investment. Each city has its own unique circumstances; Xining for example, is a center for high energy consumption industries, and the main purpose of its learning pathways is to increase its energy consumption efficiency.

Cities within the fourth tier include: Shijiazhuang, Lanzhou and Nanning. As compared to cities in the previous tiers, the fourth-tier cities do not lag behind in terms of GDP and public investment. The main weaknesses of Shijiazhuang and Lanzhou are that they have excessively high energy consumption and suffer from severe environmental pollution, whereas Nanning is incapable of providing sufficient opportunities for employment. These cities are still in the industrialization stage, and therefore have lower levels of SD ability.

As a whole, at present, the coastal cities of China have a higher level of SD ability than inland cities, cities in the south are more highly rated than those in the north, and cities that are prioritized in national policy and funding (i.e., directly-controlled municipalities, "cities under separate state planning", and Urumqi, which receives support at the policy level) also rate better than other cities that are spatially similar. A city's ability for SD will improve with further industry upgrades and enhancements in efficiency. This strengthening is indirectly related to GDP (as it increases the financial capabilities and overall development of a city), and there are also common causal factors between these two aspects (high efficiency industries will lead to high GDP and strong sustainability). Nonetheless, the correlation between GDP and SD ability is tenuous at best; in these calculations, GDP is only a weakness (in terms of SD ability) for one of the sampled cities. For most of China's major cities, developmental modes that are centered on GDP growth are already obsolete. As compared to GDP, the availability of high quality employment opportunities and improvements in the provision of public services are of greater significance for the SD of a city.

The dominance of heavy industries will restrict the continued growth of certain major cities. Major cities where heavy industries are aggregated must take effective measures to control industrial pollution, or move these polluting industries out of the city. However, this does not mean that environmental pollution only has a small impact on the remaining cities, as environmental pollution is a key factor in determining differences in efficiency between the four tiers of classification. As a whole, environmental pollution is one of the most important factors that restrict the SD ability of China's cities. Therefore, the control of pollution will significantly improve the SD ability of a city. Even the first-tier cities that have the highest efficiencies still have significant room for improvement in this aspect, since the SD ability of a city simply represents an assessment of its dynamic state [42], and does not represent a terminal point.

\section{Summaries and Conclusions}

In this study, 34 major cities in China were classified into four tiers according to their SD ability. Unlike expectations, the performance of cities in the comprehensive assessment was almost unconstrained by the total economic output. Cities with the lowest sustainable ability were strongly recommended reduction in energy consumption and pollution. In reality, both Lanzhou and Shijiazhuang are important cities with highly polluting industries, and even Shijiazhuang has three times the steel capacity of entire US. Compared with their output, most cities in the third tier use excessive labor to maintain economic activities, thus reducing their efficiencies. This implies that their industries are labor-intensive. Cities in the second tier consume excessive investments in fixed assets, showing that they are undertaking large-scale expansion and urban renewal, in response to capital appropriation; their public service investments are significantly lower than cities in the first tier. In summary, the dominant industries in each of these tiers (from low to high) are: high energy consumption and polluting industries-labor-intensive industries—fixed asset investment and service industries-innovation-related activities, quality of life, and societal services. This work has provided 
recommendations for the developmental pathways of each city (in each of the tiers). For cities in the fourth, third and second tiers that have lower levels of SD ability, the focal points for improvement are: the control of energy consumption and environmental pollution, the upgrading of industries and urban redevelopment, and the development of an environment that encourages innovation and provides ample employment. This work also provides unique developmental pathways for each city in each of the tiers, and also includes optimal learning benchmarks. In this study, it was also found that GDP is not generally a restricting factor for SD ability, since the majority of China's cities already have a high level of GDP. With the background of China's large population, in future developments towards sustainable cities, more focus should be placed on knowledge-intensive economies and balanced development, in order to prevent resource concentration from backward cities to leading cities by the polarizing effect, which causes overinflated expansion of central cities. Environmental pollution is a universal restricting factor for the SD of China's cities. Hence, pollution prevention is one of the focal points for future urban developments.

The DEA method and improved versions of this method have been used by a number of studies to evaluate SD in several regions of China. These studies have generally focused on provincial regions (autonomous regions and directly-controlled municipalities), whereas this study treats cities as DMUs and appropriately restricts the spatial range of the study. This has resulted in precise and targeted results, and circumvents issues related to excessive sample differences and internal sample heterogeneity. As compared to previous related studies, DMUs that significantly contradict common understandings were not produced in this study. It is thus shown that the appropriate restriction of sample space and range is important for the rationality of the results that are obtained from the DEA model during efficiency evaluations. Furthermore, the component factors for SD have been treated in a comprehensive manner, on the basis of previous studies on economic, energy resource and environmental factors. Evaluative indicators for societal development were introduced so that all three aspects of SD could be simultaneously evaluated within this study, thus producing a more holistic evaluation of SD ability. Due to restrictions imposed by the availability of data, this study only includes the assessment of static states. Subsequent studies may also include a time perspective, so that dynamic evaluations can be performed to analyze the evolution and fluctuation of a city's SD ability.

According to China's governmental website (www.gov.cn), SD has been an important part of China's national strategy since 2012. The SD of cities is an important component of the nation's SD since a majority of China's population now live in urban environments. Urban sustainability is therefore a highly significant issue. Like other economic phenomena, the development of cities must adhere to certain intrinsic patterns, and a stage of development cannot be "skipped" in an arbitrary manner. In this work, China's major cities were classified according to their SD abilities, and pathways for improvement were proposed for each city and each tier of classification. This work is of significant value for guiding the planning of cities, and policy makers may also benefit strongly from our findings. Therefore, we expect that the SD of China's cities will continue to improve over time.

Acknowledgments: This work was finished in National Central University (NCU). The authors would like to thank School of Management at NCU for excellent support. We acknowledge the editors and the anonymous reviewers for insightful suggestions on this work.

Author Contributions: Shih-Heng Yu and Yu Gao conceived and designed the study, analyzed the data, structured the article and wrote the draft. Yih-Chearng Shiue reviewed and edited the manuscript. All authors have read and approved of the manuscript.

Conflicts of Interest: The authors declare no conflict of interest.

\section{References}

1. Shen, L.; Peng, Y.; Zhang, X.; Wu, Y. An alternative model for evaluating sustainable urbanization. Cities 2012, 29, 32-39. [CrossRef]

2. Steurer, R.; Langer, M.E.; Konrad, A.; Martinuzzi, A. Corporations, stakeholders and sustainable development I: A theoretical exploration of business-society relations. J. Bus. Ethnics 2005, 61, 263-281. [CrossRef] 
3. Hutchins, M.J.; Sutherland, J.W. An exploration of measures of social sustainability and their application to supply chain decisions. J. Clean. Prod. 2008, 16, 1688-1698. [CrossRef]

4. Balmford, A.; Bruner, A.; Cooper, P.; Costanza, R.; Farber, S.; Green, R.; Jenkins, M.; Jefferiss, P.; Jessamy, V.; Madden, J.; et al. Economic reasons for conserving wild nature. Science 2002, 297, 950-953. [CrossRef] [PubMed]

5. Pahl-Wostl, C.; Tàbara, D.; Bouwen, R.; Craps, M.; Dewulf, A.; Mostert, E.; Dagmar, R.; Taillieu, T. The importance of social learning and culture for sustainable water management. Ecol. Econ. 2008, 64, 484-495. [CrossRef]

6. Gibbs, D. Regional development agencies and sustainable development. Reg. Stud. 1998, 32, 365-368. [CrossRef]

7. Lu, W.M.; Lo, S.F. A Benchmark-Learning Roadmap for Regional Sustainable Development in China. J. Oper. Res. Soc. 2007, 58, 841-849. [CrossRef]

8. Sueyoshi, T.; Yuan, Y. China's regional sustainability and diversified resource allocation: DEA environmental assessment on economic development and air pollution. Energy Econ. 2015, 49, 239-256. [CrossRef]

9. Zhou, P.; Ang, B.W. Linear programming models for measuring economy-wide energy efficiency performance. Energy Policy 2008, 36, 2911-2916. [CrossRef]

10. Wang, K.; Wei, Y.M.; Zhang, X. Energy and emission efficiency patterns of Chinese regions: A multi-directional efficiency analysis. Appl. Energy 2013, 104, 105-116. [CrossRef]

11. Tao, X.; Wang, P.; Zhu, B. Measuring the interprovincial $\mathrm{CO}_{2}$ emissions considering electric power dispatching in china: From production and consumption perspectives. Sustainability 2016, 8, 506. [CrossRef]

12. Chen, Y.; Cook, W.D.; Du, J.; Hu, H.; Zhu, J. Bounded and discrete data and Likert scales in data envelopment analysis: Application to regional energy efficiency in China. Ann. Oper. Res. 2017, 255, 347-366. [CrossRef]

13. Yang, Q.; Wan, X.; Ma, H. Assessing green development efficiency of municipalities and provinces in China integrating models of super-efficiency DEA and malmquist index. Sustainability 2015, 7, 4492-4510. [CrossRef]

14. Charnes, A.; Cooper, W.W.; Li, S. Using data envelopment analysis to evaluate efficiency in the economic performance of Chinese cities. Socio-Econ. Plan. Sci. 1989, 23, 325-344. [CrossRef]

15. Zhu, J. Data envelopment analysis with preference structure. J. Oper. Res. Soc. 1996, 47, 136-150. [CrossRef]

16. Yuan, X.; Wang, Q.; Wang, K.; Wang, B.; Jin, J.; Wei, Y. China's regional vulnerability to drought and its mitigation strategies under climate change: Data envelopment analysis and analytic hierarchy process integrated approach. Mitig. Adapt. Strateg. Glob. Chang. 2015, 20, 341. [CrossRef]

17. Yang, W.; Lee, Y.; Hu, J. Urban sustainability assessment of taiwan based on data envelopment analysis. Renew. Sustain. Energy Rev. 2016, 61, 341-353. [CrossRef]

18. Li, X.; Xu, X.; Chen, H. Temporal and spatial changes of urban efficiency in the 1990s. Acta Geogr. Sin. 2005, 60, 615-625.

19. Honma, S.; Hu, J. Total-factor energy efficiency of regions in japan. Energy Policy 2008, 36, 821-833. [CrossRef]

20. Storto, C.L. Ecological efficiency based ranking of cities: A combined DEA cross-efficiency and shannon's entropy method. Sustainability 2016, 8, 124. [CrossRef]

21. Mega, V. Our city, our future: Towards sustainable development in European cities. Environ. Urban. 1996, 8, 133-154. [CrossRef]

22. Charnes, A.; Cooper, W.W.; Rhodes, E. Measuring the efficiency of decision making units. Eur. J. Oper. Res. 1978, 2, 429-444. [CrossRef]

23. Tone, K. Slacks-based measure of efficiency in data envelopment analysis. Eur. J. Oper. Res. 2001, 130, 498-509. [CrossRef]

24. Zhou, P.; Ang, B.W.; Poh, K.L. Slacks-based efficiency measures for modeling environmental performance. Ecol. Econ. 2006, 60, 111-118. [CrossRef]

25. Zhu, Z.; Miao, J.; Cui, W. Measuring regional eco-efficiency: A non-oriented slacks-based measure analysis. Int. J. Earth Sci. Eng. 2014, 6, 2520-2527.

26. Seiford, L.M.; Zhu, J. Context-dependent data envelopment analysis-Measuring attractiveness and progress. Omega 2003, 31, 397-408. [CrossRef]

27. Lim, S.; Bae, H.; Lee, L.H. A study on the selection of benchmarking paths in DEA. Expert Syst. Appl. 2011, 38, 7665-7673. [CrossRef] 
28. Wu, J.; Zhu, Q.; Liang, L. $\mathrm{CO}_{2}$ emissions and energy intensity reduction allocation over provincial industrial sectors in china. Appl. Energy 2016, 166, 282-291. [CrossRef]

29. Bi, G.; Song, W.; Wu, J. A clustering method for evaluating the environmental performance based on slacks-based measure. Comput. Ind. Eng. 2014, 72, 169-177. [CrossRef]

30. Park, J.; Sung, S. Integrated approach to construction of benchmarking network in DEA-based stepwise benchmark target selection. Sustainability 2016, 8, 600. [CrossRef]

31. Morita, H.; Hirokawa, K.; Zhu, J. A slack-based measure of efficiency in context-dependent data envelopment analysis. Omega 2005, 33, 357-362. [CrossRef]

32. Li, L.B.; Hu, J.L. Ecological total-factor energy efficiency of regions in China. Energy Policy 2012, 46, $216-224$. [CrossRef]

33. Cooper, W.W.; Seiford, L.M.; Tone, K. Data Envelopment Analysis: A Comprehensive Text with Models, Applications, References and DEA-Solver Software, 2nd ed.; Springer: New York, NY, USA, 2007.

34. Shiu, A.; Lam, P. A data envelopment analysis of the efficiency of China's thermal power generation. Util. Policy 2001, 10, 75-83.

35. Zhang, N.; Lior, N.; Jin, H. The energy situation and its sustainable development strategy in China. Energy 2011, 36, 3639-3649. [CrossRef]

36. Wang, K.; Wei, Y. China's regional industrial energy efficiency and carbon emissions abatement costs. Appl. Energy 2014, 130, 617. [CrossRef]

37. Hu, J.; Wang, S. Total-factor energy efficiency of regions in China. Energy Policy 2006, 34, $3206-3217$. [CrossRef]

38. Zhang, B.; Bi, J.; Fan, Z.; Yuan, Z.; Ge, J. Eco-efficiency analysis of industrial system in China: A data envelopment analysis approach. Ecol. Econ. 2008, 68, 306-316. [CrossRef]

39. Wu, X.; Tan, L.; Guo, J.; Wang, Y.; Liu, H.; Zhu, W. A study of allocative efficiency of PM $_{2.5}$ emission rights based on a zero sum gains data envelopment model. J. Clean. Prod. 2016, 113, 1024-1031. [CrossRef]

40. Saunders, P.; Shang, X. Social security reform in China's transition to a market economy. Soc. Policy Adm. 2001, 35, 274-289. [CrossRef]

41. Cai, F.; Chan, K.W. The global economic crisis and unemployment in China. Eurasian Geogr. Econ. 2009, 50, 513-531. [CrossRef]

42. Banister, D. Barriers to the implementation of urban sustainability. Int. J. Environ. Pollut. 1998, 10, 65-83. [CrossRef]

(C) 2017 by the authors. Licensee MDPI, Basel, Switzerland. This article is an open access article distributed under the terms and conditions of the Creative Commons Attribution (CC BY) license (http:/ / creativecommons.org/licenses/by/4.0/). 